\title{
Iranian transplant
}

\author{
Iran is in a hurry to industrialise, and needs teachers \\ and technicians. Peter Newmark, \\ just back from Tehran, assesses the problems
}

\begin{abstract}
A VEN a brief visit is enough to show that the development of science and technology in Iran is hurtling forward, somewhat blindly, along the paths well worn by the Western countries. Using but a tiny portion of his oil revenues, the Shah (or, more properly, the Shahanshah or King of Kings) has instigated an immense programme of higher education to produce the technologists and scientists that his country nteds to hoist it from "developing" to "developed" status. But all the oil in Persia cannot make the hoisting operation run smoothly.
\end{abstract}

In other circumstances a country with an illiteracy rate of $50 \%$ would focus its attention on a programme of general education at the initial expense of higher education. Iran, however, is in a hurry, and under few enough financial restraints that it can undertake parallel improvements at all levels of learning. The Shah has therefore recently introduced free compulsory education to the age of 13 and, last year, added free university education in return for a commitment to join the civil service for a period of twice the length of the degree course.

The consequent demand for higher education has greatly exceeded predictions. This year there are eight applications for every university place that is available, in spite of the fact that the number of places has doubled in less than five years. In part the additional demand will be met by the introduction this year of a Free University on the radio and television networks (based on and bought from Britain's Open Univorsity).

The clamour for higher education is a consequence of over-eager policies, particularly in a country where the the material advantages that accrue to the highly educated minority can all too clearly be seen. The problem is both to meet the demand and to channel it sensibly. In the first place there is a drastic need to reinvest many of the educated into the teaching system, which at present suffers from manpower shortages in many areas.

The other priority must be to solve Iran's shortage of skilled technicians. That problem is the classic one faced by any country that suddenly finds itself able to buy up the highly advanced technology of the developed countries-be it a nuclear power plant or an electron microscope-but without the trained technicians needed to run and maintain the equipment. For example, Dr Zarghami, Chancellor of the Arya-Mehr University of Technology in Tehran, estimates that the ccuntry presently lacks 2,000 of the 28,000 graduate engineers that it requires. But worse is to come. In ten years time he predicts that Iran will only be able to provide 60,000 of the 75,000 graduate engineers needed.

That problem is essentially insoluble ${ }_{\alpha}^{\alpha}$ in the short term. It is not even clear that the output of graduate engineers can really be more than doubled in ten years despite the founding of a second campus of the University of AryaMehr. The campus, a self-contained city, will be situated a few miles outside the city of Isfahan, 200 miles south of Tehran. When fully functional the Isfahan campus will be the largest technical university in the Middle East with the possible exception of the Technion in Haifa. In ten years time it will have 10,000 undergraduates and 3,000 graduate students.

Another part of the plan to increase the number of technicians is the intention of the Ministry of Science and Higher Education to collaborate with Iranian industry in setting up an Industrial Training Complex. Its sole function would be to turn out specialist technicians to satisfy the requirements ol industry. At a lower level there is already a requirement that any factory which employs more than 500 people has attached to it a school for the children of the factory workers. Such schools can instruct the children in at least some of the basic skills required for them to follow their parents into the factory.

In spite of all these plans the shortage of specialist technicians will still be increasing rather than decreasing for at least the next ten years. The gap will have to be met by offering high salaries to skilled personnel either from the West or from other Middle East countries. Recruitment from the latter, to judge from accounts of the recent Islamic Solidarity Conference in Science and Technology, is bound to provoke regional discontent.

With such a shortage of teachers and technicians it would not be surprising were the progress of basic scientific research to be in jeopardy. On the contrary, however, a clear and strong commitment to the establishment of basic research is evident both in universities and in separate research insti-

\section{Sorry, for copyright reasons some images on this page may not be available online}

\section{Iranian village}

tutes in Iran, although fears are expressed in some quarters that the level of future support will depend very directly on the sales of oil which, together with the revenue thereby derived, fell sharply last year.

In the meantime the administration of research is very much along Western lines. For example, last year saw the creation of the National Scientific Research Council, a central policy body. The council is responsible for the coordination, supervision and funding of research. The latter will be subject to the usual kind of peer group approval and will take into account the council's suggestion of priority areas for research. At the moment, however, even Dr Parsa, Deputy Minister for Science and Research, admits that priorities are largely hypothetical since any scientist who is of reasonably high calibre (and who is at least not openly critical of the Shah's policies) is likely on those grounds alone to funded. That situation is likely to remain for some considerable time until the number of good research scientists reaches a critical mass. Demand will then no doubt start to outstrip the supply of funds.

Until (and to ensure that) the critical mass is reached, it is essential that Iranian scientists undergo part of their training overseas and that international contacts are lovingly fostered. At present about 50,000 Iranians are overseas partaking of some form of higher education. Many science graduates like to obtain their PhD overseas, but Dr Mofidi, the Vice-Chancellor of Tehran University, would prefer to see overseas training at a post-doctoral level so that it can be based on a genuine familiarity with what awaits the scientist on his or her return. And return he or she almost certainly will, given the very favourable job market 
in Iran compared to the West. That may also enable Iran to buy up a number of Western scientists to tide them over the next few years.

International contacts are necessary not only for the placing of students oveaseas but also for the development of research programmes. Contacts are encouraged through sabbatical leave every fourth year and by financing international meetings in Iran. A recent example was the four-day meeting on the eukaryotic genome at the University of Tehran in May. About 40 Western experts were imported to expound on their research before an audience of about the same number of local scientists. No doubt the prestige of such an occasion is as important as the chance of making contacts; the actual symposium presentation probably come a poor third in real value.

Whereas Iran is presently looking determinedly to the West for international collaboration and advice, many Iranian scientists would like to develop a more regional approach. In particular that would make sense for programmes of "regional technology" in, for example, solar energy, desalination and arid zone research. Already there are programmes of cooperation with various Arab countries, Turkey and Pakistan. A bigger attraction for some would be Israel because of her scientific expertise both in basic research and in "regional technology". Although there is already a certain

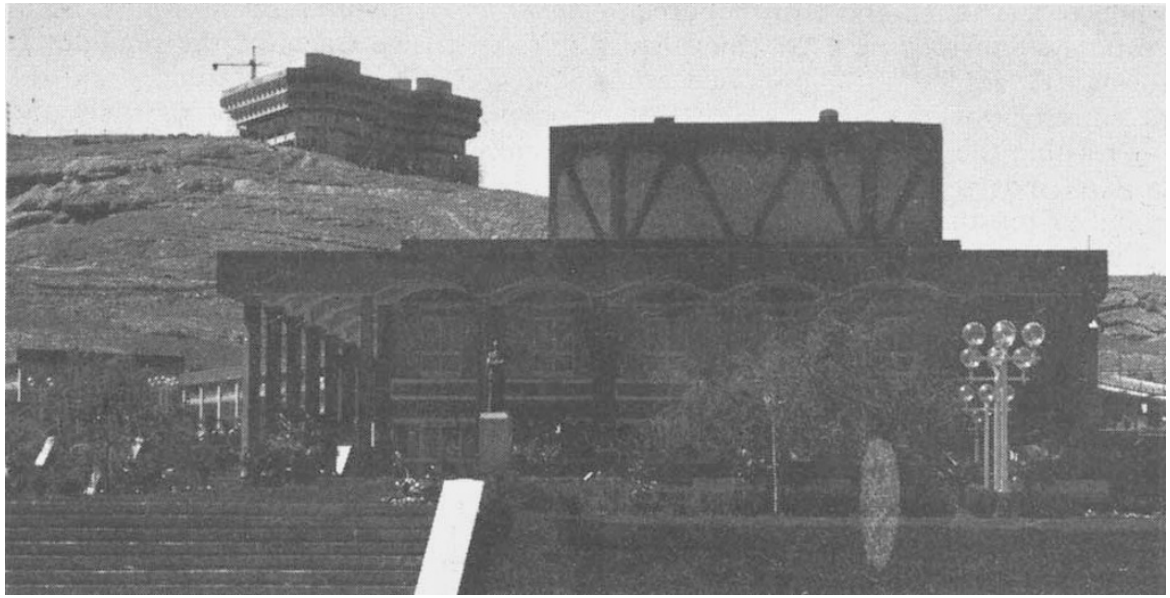

University of Shiraz, Iran

amount of informal contact with Israel, pclitical factors rule out any real cooperation.

There is in Iran an ancient tradition of science and technology. Its origins lie in the precise requirements of the Islamic faith for the time and direction of prayer. But tradition has nothing to offer to the new generation of Iranian scientists who are whole-heartedly committed to transplanting Western science, warts and all, to the Middle East. Whilst recognizing the need for a scientific discipline to have roots in the society that supports it, they argue that Iranian society is in the process of general change and in time will be ready to nourish the roots of Westernstyle science. The concurrent argument is that without generous support of basic research, no roots, in the form of Iranian eminence, will form.

The transplantation of Western values in science and much besides has, not surprisingly, led to certain problems in the universities as well as in Iranian society at large. In particular there are difficulties of adjustment for come from poorer, more traditional backgrounds. The result is a high dropout rate and sporadic political dissent which is ruthlessly suppressed. Overall, the Shah will not for the present tolerate any public questioning of his drive to make Iran a military and industrial force to be reckoned with. the growing number of students who

\section{Conservation in Iran}

\section{Peter D. Moore, recently in Iran, looks at attempts to conserve wildlife in a fast changing country}

$\mathbf{N}^{A}$ ATURE conservation in the industrialised nations is said to be a cause associated primarily with the middle classes. Developing countries often see it as a worthwhile economic exercise, since wildlife parks can be a major tourist attraction providing foreign currency. But in Iran it is neither of these. There is little tourist industry apart from that which centres upon the archaeological rather than wildlife potential of the country. Yet conservation ranks high among the priorities of the government. The Iranian Department of the Environment, headed by Eskandar Firouz, is (unlike the British establishment of the same name) primarily concerned with environmental research and practical management problems in Iran's cities, rural areas, wildlife parks and reserves, and around its Persian Gulf and Caspian Sea coasts.

The sheer size of the country (about three times the area of France) and its altitudinal variation (from $50 \mathrm{~m}$ below sea level at the Caspian to $5,700 \mathrm{~m}$ in the Elburz mountains near Tehran) results in a wide range of habitats and a high diversity of wildlife. About $80 \%$ of Iran is over $1000 \mathrm{~m}$ in altitude: much of this lies in a great central plateau surrounded by high mountains, the physical isolation of which could account for the high proportion of endemics in the Iranian flora.

To ensure that examples of all the major habitats are conserved, the Environment Department has established over 40 wildlife parks and protected areas, covering a combined area larger than Switzerland. The broad-leaved forests of the Caspian area still contain wild pig, brown bear and the Persian subspecies of fallow deer, which has been rescued from the verge of extinction. Tigers were reported from this region in the first half of the century, but are now feared extinct.
The Caspian lowlands also contain some important wetland areas which serve as winter feeding grounds for large populations of wildfowl that breed in western Siberia. Other wetland areas in Iran are mainly in the west, especially the saline lakes: the largest is Lake Rezaiyeh, which extends over 3,000 ha and supports breeding populations of 25,000 pairs of greater flamingo and 1,400 pairs of white pelican. The wetlands of the Gulf in the south of Iran include the Eastern Mesopotamian marshes and the rivers of Iranian Baluchistan, where the marsh crocodile still survives at the western limit of its range.

The wealth of wetland habitats which Iran contains, coupled with the threat which is posed to them by increasing industrialisation, may explain why Iran has become a global trend-setter in the field of wetland conservation. In February 1971, a Convention was agreed at an international conference in Ramsar, Iran, by which all signatory member countries should designate at least one of their wetland sites for inclusion in a list of wetlands of international importance. Iran was the second country to ratify this treaty, 